\title{
Intraoperative electrical stimulation in awake craniotomy: methodological aspects of current practice
}

\author{
Andrea Szelényi, M.D., Ph.D., ${ }^{1}$ Lorenzo Bello, M.D., ${ }^{2}$ Hugues Duffau, M.D., Ph.D., ${ }^{3}$ \\ Enrica Fava, M.D., Ph.D., ${ }^{2}$ Guenther C. Feigl, M.D., ${ }^{4}$ Miroslav Galanda, M.D., Ph.D., 5 \\ Georg Neuloh, M.D. ${ }^{6}$ Francesco Signorelli, M.D. ${ }^{7}$ Francesco Sala, M.D., ${ }^{8}$ \\ and Workgroup for Intraoperative Management in Low-Grade Glioma Surgery \\ within the European Low-Grade Glioma Network
}

\begin{abstract}
${ }^{1}$ Department of Neurosurgery, Johann Wolfgang Goethe University, Frankfurt am Main, Germany; ${ }^{2}$ Department of Neurosurgery, University of Milan, Italy; ${ }^{3}$ Department of Neurosurgery, University of Montpellier, France; ${ }^{4}$ Department of Neurosurgery, University of Tübingen, Germany; ${ }^{5}$ Department of Neurosurgery, University Hospital, Banská Bystrica, Slovakia; ${ }^{6}$ Department of Neurosurgery, University of Bonn, Germany; ${ }^{7}$ Department of Neurosurgery, University of Catanzaro; and ${ }^{8}$ Department of Neurosurgery, University of Verona, Italy
\end{abstract}

\begin{abstract}
There is increasing evidence that the extent of tumor removal in low-grade glioma surgery is related to patient survival time. Thus, the goal of resecting the largest amount of tumor possible without leading to permanent neurological sequelae is a challenge for the neurosurgeon. Electrical stimulation of the brain to detect cortical and axonal areas involved in motor, language, and cognitive function and located within the tumor or along its boundaries has become an essential tool in combination with awake craniotomy. Based on a literature review, discussions within the European Low-Grade Glioma Group, and illustrative clinical experience, the authors of this paper provide an overview for neurosurgeons, neurophysiologists, linguists, and anesthesiologists as well as those new to the field about the stimulation techniques currently being used for mapping sensorimotor, language, and cognitive function in awake surgery for low-grade glioma. The paper is intended to help the understanding of these techniques and facilitate a comparison of results between users. (DOI: 10.3171/2009.12.FOCUS09237)
\end{abstract}

\section{KEY WORDS • awake craniotomy • direct cortical stimulation low-grade glioma surgery $\quad \bullet \quad$ brain mapping}

$\mathrm{T}$ HE direct intraoperative application of electric current onto the human cortex for localizing and activating function dates back to the 1930 s. ${ }^{10,20,37}$ Its definite impact on preserving function in the resection of low-grade gliomas has been reported. ${ }^{6-8,13,18,36}$ Nevertheless, methodological rigor and the meticulous performance of mapping procedures are indispensable to avoid any false-positive or false-negative stimulation results, which could lead to inadequate tumor resection or cause permanent neurological deficits. If all the technical rules are not respected faithfully, inaccurate results will create a false sense of security, which could lead to undesired surgical results and permanent neurological sequelae. Based on published material, personal experience, and discussions with members of the European Low-Grade Glioma Group who are dedicated to the intraoperative stimulation procedure, the most important aspects of

Abbreviations used in this paper: CUSA = Cavitron ultrasonic aspirator; DT = diffusion tensor; ECoG = electrocorticography; $\mathrm{EMG}=$ electromyography; $\mathrm{MEP}=$ motor evoked potential. brain mapping during surgeries in awake patients are presented and reviewed.

The purpose of the mapping procedure is to reliably identify cortical areas and subcortical pathways involved in motor, sensory, language, and cognitive function. Although similar techniques are utilized, the application of mapping at different centers involves a diversity of approaches.

\section{Electrical Stimulation}

The technical aspects of electrical stimulation include the stimulator device; the stimulation parameters consisting of the individual pulse type, pulse width, frequency of stimulation, and applied intensity; and the stimulation probe being used to deliver the electric current.

\section{Stimulator Device}

For brain mapping purposes, constant-current stimulators are considered safer and more reliable because they deliver the preset current independently from the imped- 


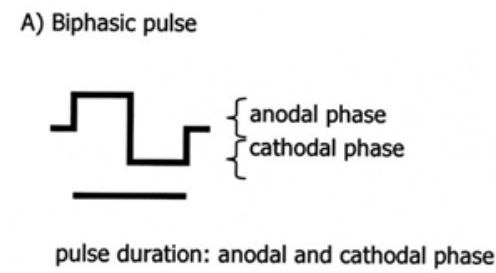

B) Monophasic pulse

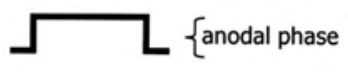

pulse duration: anodal phase

FIG. 1. Schematic of monophasic and biphasic pulse forms.

ance of the cortical or subcortical surface. Conversely, in constant-voltage stimulators, the delivered current also depends on the impedance. Hence, if impedance decreases, the amount of current delivered can dramatically increase and compromise the safety of the procedures. An extensive discussion of the differences between constantcurrent and constant-voltage stimulators is beyond the scope of this review.

\section{Stimulation Parameters}

For brain mapping, a low frequency paradigm has been established, consisting of the application of short pulse trains with frequencies of $25-60 \mathrm{~Hz}$. The most commonly applied frequencies are $50 \mathrm{~Hz}$ (Europe) or 60 $\mathrm{Hz}$ (North America).

The individual pulse is rectangular and either monophasic or biphasic (Fig. 1). As described in the first experiments, cortical stimulation is more effective with anodal current; that is, a lower stimulation intensity is needed to see a stimulation effect. ${ }^{21,23}$ Thus, the first phase of the pulse should be anodal. If a monophasic pulse is used, it should be anodal (or positive); if a biphasic pulse is used, it should be in an anodal/cathodal mode. The anodal phase duration can vary between 0.2 and $0.5 \mathrm{msec}$. In applying a biphasic current, the duration of the pulse includes both the positive and negative phases. Therefore, only half of the pulse duration is anodal and effective for stimulation-meaning that a monophasic pulse of $0.5 \mathrm{msec}$ delivers the same anodal current as a biphasic pulse of $1 \mathrm{msec}$. However, as the charge is dependent on pulse duration (charge [Asec] = pulse duration $[\mathrm{sec}] \times$ intensity $[\mathrm{A}]$ ), the charge applied to the brain using a biphasic pulse is twice that applied using the same current but with a monophasic pulse. For safety considerations, the maximum stimulation intensity should not exceed $40 \mu \mathrm{C} / \mathrm{cm}^{2} /$ phase and is commonly limited to $20 \mathrm{~mA} .^{1}$ For a detailed physical background regarding monopolar versus bipolar stimulation techniques see the study by Kombos and Süss. ${ }^{28}$

Historically, at times when only uncoupled stimulators were available, a biphasic pulse was seen to be less neurotoxic as the reversed pulse could minimize those effects. ${ }^{40}$ With the utilization of coupled stimulators and limited application times during surgical procedures, neurotoxic effects have not been described. 2,22,31,40,41

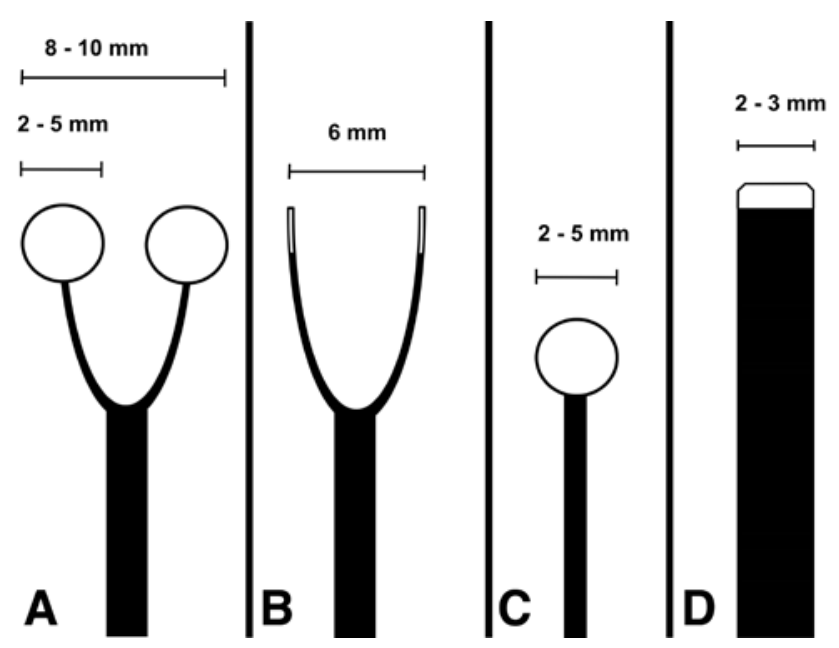

FIG. 2. Schematic of probes used for bipolar stimulation with ball tips (A) or straight tips (B) and for monopolar stimulations with a ball tip (C) or straight tip (D).

\section{Stimulation Probe}

The use of a bipolar probe with 2 tips separated by 6-10 $\mathrm{mm}$ has become standard (Fig. 2). An interelectrode distance $>10 \mathrm{~mm}$ seems to favor the elicitation of large pyramidal tract neurons..$^{25}$ Alternatively, a monopolar probe with a frontal reference electrode can be used. The distribution of the electric field differs between monopolar and bipolar probes. Given the same stimulation intensities, a monopolar probe provides a homogeneous radiant spreading electric field, which leads to lower current densities in the area surrounding the reference electrode but has the benefit of more spacious stimulation effects. With this probe the probability of stimulating nervous tissue at a more distant site increases. In contrast, stimulation with a bipolar probe creates an electric field in which the current density is more homogeneous and the electric field lines between both poles are close to parallel (Fig. 3)..$^{32,38}$ If monopolar and bipolar electrodes have the same shape, the current density close to the stimulating electrodes is the same and the greatest.

\section{Documentation of Stimulation's Effect}

\section{Observation of the Patient}

The most simple and most complex task for the examiner is observing the patient's reaction to stimulation. Movement can be observed and categorized by its complexity. Clonic movement relates to stimulation of the primary motor area, whereas tonic movement is more related to stimulation of the premotor area (Area 6). Furthermore, the absence of any induced movement should be tested for negative motor phenomena (see Mapping of Motor Function).

\section{Recording Electrodes}

Small movements or movements at distant sites can go unrecognized. Simultaneous brain mapping and monitoring of muscle activity by continuous EMG recording (either surface electrodes or needle electrodes) can be 


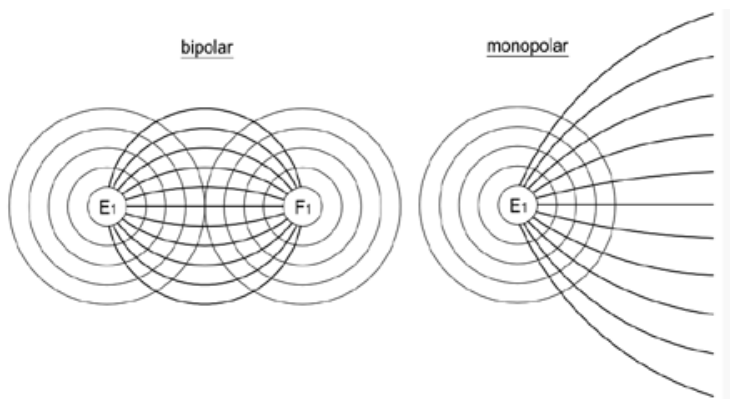

FIG. 3. Schematic of electric field distribution in bipolar (left) and monopolar (right) stimulations.

helpful. ${ }^{50}$ Electromyography-complementary to ECoGalso allows for early detection of the spreading of muscle activation over a limb as a sign of seizure. These data can be stored and used for offline analysis and for the purpose of documentation. To record EMG activity, subdermal needle electrodes are used and are surprisingly well tolerated even during awake procedures. Alternatively, surface EMG electrodes placed in the belly-tendon fashion can be used.

\section{Mapping in Awake Patients}

As stimulation-induced movements are easy to observe, it is typically recommended to start with the mapping of motor function. The presence of a speech therapist, neuropsychologist, or neurologist is very important for observation and judgment, especially for language and cognitive function. It is highly recommended to introduce members of the surgical team to the patient and to explain the intraoperative procedure as well as the testing to the patient at least a day prior to surgery. The patient might feel uncomfortable experiencing involuntary movement or the inhibition of voluntary movement and language, which could lead to feelings of fear and angst and might be accompanied by an alteration of vital and vegetative signs such as nausea, hypertonia, and tachycardia. Moreover, patients might conclude from positive testing that the tumor has invaded important cortical structures and thus that the tumor surgery might not be successful. Some patients experience overwhelming fear, which could interfere with further testing and even the whole surgical procedure. In such patients, ECoG is helpful for ruling out nonconvulsive but focal temporal seizures. The patient's guidance is very important, and therefore each step of the testing and stimulation procedure should be announced. Patients should be carefully examined and asked about any sensation, feelings, or movements, especially the contraction of pharyngeal muscles, which might not be observed by the examiner.

\section{Mapping of Motor Function}

While performing direct cortical stimulation, the stimulation intensity should be increased stepwise by 1 $\mathrm{mA}$ until a movement or EMG response is observed. This stimulation intensity should be used for further mapping of sensorimotor, language, and cognitive function. One to $2 \mathrm{msec}$ duration of stimulation is sufficient to induce

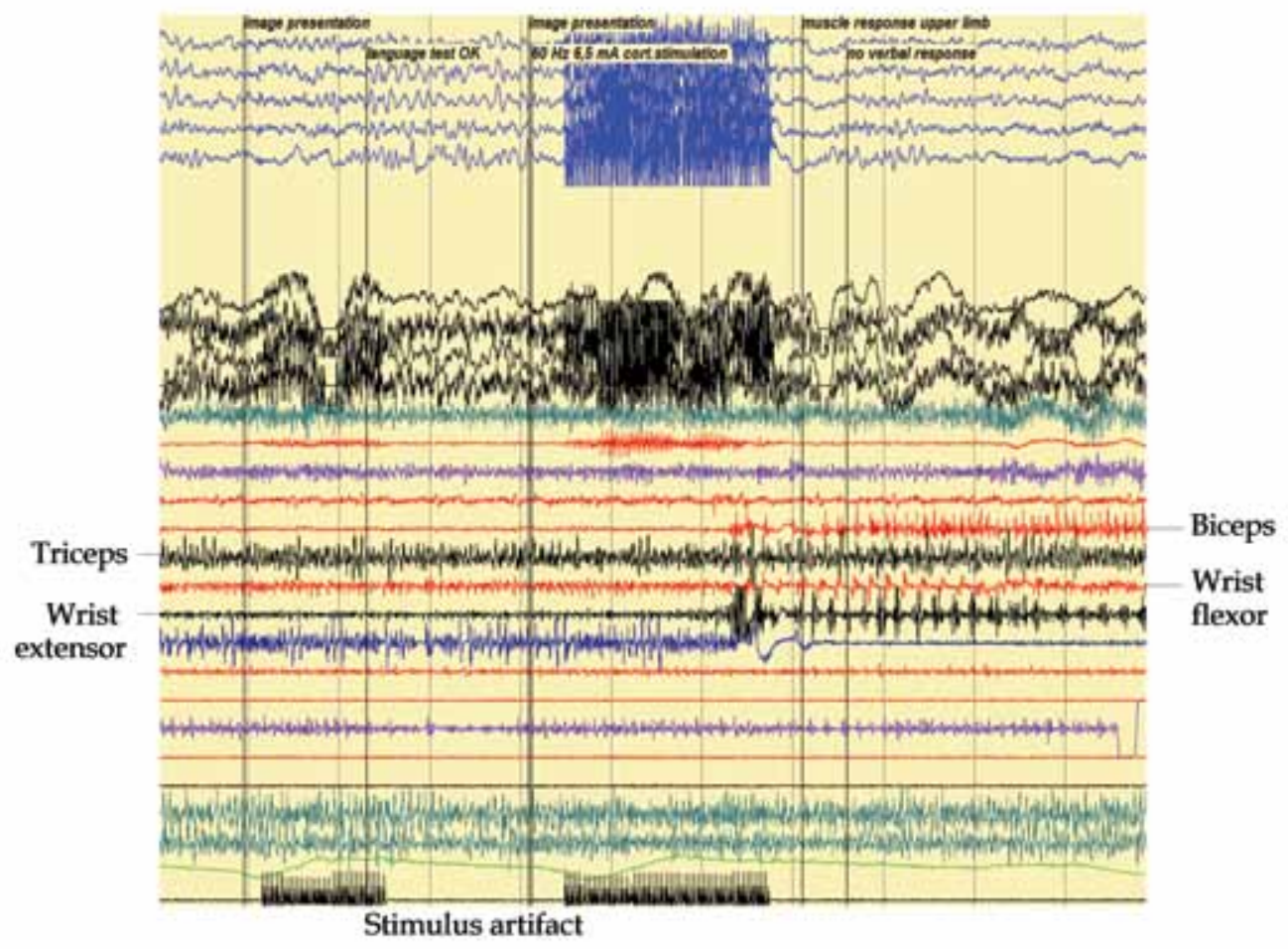

FIG. 4. Awake surgery ECoG (Traces 1-4), surface electroencephalography (Traces 6-9), and EMG traces (remaining traces) showing $60-\mathrm{Hz}$ stimulations $(6.5 \mathrm{~mA})$ of the premotor cortex. During stimulation for language testing, a speech arrest was induced, followed by clonic jerks in the right upper limb muscles. 


\begin{tabular}{ll}
\hline stimulation & stimulate entire exposed cortical area every $5 \mathrm{~mm}^{2}$ (according to probe spacing) \\
stimulate every site at least 3 times \\
never stimulate same cortical area twice successively \\
always perform checking test w/o stimulation btwn 2 stimulations \\
start w/ motor mapping: movement is easy to observe \\
for cognitive \& language tasks, stimulation should be started before presentation of the item \\
for subcortical mapping, imagine path of the white matter tract stimulated \& raise the intensity by 2 mA, repeating the stimulation \\
very regularly while mapping the path tract \\
mark positive areas w/ small paper tag \\
document anatomical relations \\
special advice: \\
1) do not stop mapping after identifying only 1 eloquent site, but search for possible redundancies; a negative mapping does not \\
protect, but creates the problem of questionable stimulation reliability \\
2) an area invaded by a tumor has an increased impedance, which could justify an increase in the intensity of stimulation \\
parameters relative to neighboring healthy tissue, especially in cases in which gliomas infiltrate functional areas \\
irrigate w/ cold Ringer solution or isotonic NaCl; do not restimulate immediately afterwards \\
special advice: stimulation intensity should be decreased during control stimulations in areas of decompressed brain tissues to \\
limit the risk of inducing a seizure; no-response sites at beginning of surgery should always be retested after decompression \\
intraop ECoG can be useful in detecting afterdischarges
\end{tabular}

movement if the primary motor cortex is stimulated. Longer durations of stimulus $(2-4 \mathrm{msec})$ are required to induce motor responses from secondary motor areas. Electromyography can be used to record motor phenomena, showing even low-amplitude muscle responses and the onset of clonic muscle activity (Fig. 4).$^{50}$ Mapping of motor function can be performed in both awake and anesthetized patients. In awake patients, both muscle activation and muscle inhibition should be investigated, following a protocol related to the site of surgery. The absence of movement might be explained by a stimulation-induced inhibition of movement. In such cases, the testing of negative motor phenomena is helpful for identifying associative motor areas; ${ }^{30}$ that is, the patient is asked to perform a continuous movement-for example, alternating extension and flexion of the wrist-which is inhibited by the stimulation. Once a movement is observed, the whole of the exposed cortical area is systematically mapped every $5 \mathrm{~mm}^{2}$ (according to the probe spacing). The placement of sterile tags with numbers or letters on stimulationpositive spots is helpful for visualizing the cortical areas involved in motor, cognitive, or language function. ${ }^{14,37} \mathrm{~A}$ meticulous drawing of the anatomy or a photograph and notes describing the evoked phenomena document the testing as well as help with further surgical planning and intraoperative reference.

\section{Mapping of Language and Cognitive Function}

For the mapping of language and cognitive function, the patient's compliance is very important, as is the close cooperation among members of the participating medical team. For stimulation-induced interference with speech, language, and cognition, the duration of the stimulus must be longer than that for motor mapping. The duration of stimulation is commonly set to 3-4 seconds. To exclude occasional noncompliance or temporary impairment related to a nonconvulsive seizure, every stimulation should start after presentation of the material has started and the patient has said an introductory sentence. ${ }^{24}$ As repetitive stimulation can trigger seizures (see Side Effects), one could use an alternating testing mode; that is, one in which the patient continuously performs tasks, and each task with stimulation is followed by a task with sham stimulation (Table 1).

During resection of the tumor, continuous assessment of function as well as the potential risk of injury is necessary to maximize the extent of resection and prevent iatrogenic injury. Continuous clinical assessment during the resection is alternated with cortical and subcortical mapping and specific testing of the function anatomically closest to the resection site. As subcortical pathways might be involved within the tumor and at risk during resection, intermittent subcortical stimulation and testing has been shown to be effective at successfully preventing iatrogenic injury. $5,13,15,16,26,29$

\section{Motor Function}

For continuous monitoring of motor function in addition to periodical cortical/subcortical mapping, intentional movement of the patient can be continuously assessed. However, because this process can be exhausting for the patient and fatigue can mimic paresis, the only way to truly continuously assess the functional integrity of the motor pathways is to perform MEP monitoring.

For this purpose, continuous direct cortical stimulation of the precentral gyrus can be performed with a modified train-of-five technique. This technique, introduced for surgery in anesthetized patients, has been described as sensitive in detecting dysfunction of the motor cortex and the corticospinal tract. ${ }^{33-35,46-48}$ A strip electrode containing 4-8 electrodes must be placed over the precentral gyrus. In awake patients a single stimulus or a short train consisting of 2-4 pulses (individual pulse width $0.3-0.5 \mathrm{msec}$, anodal constant-current stimulation; interstimulus interval $4 \mathrm{msec}$, stimulation close to motor threshold) is usually sufficient to elicit muscle 


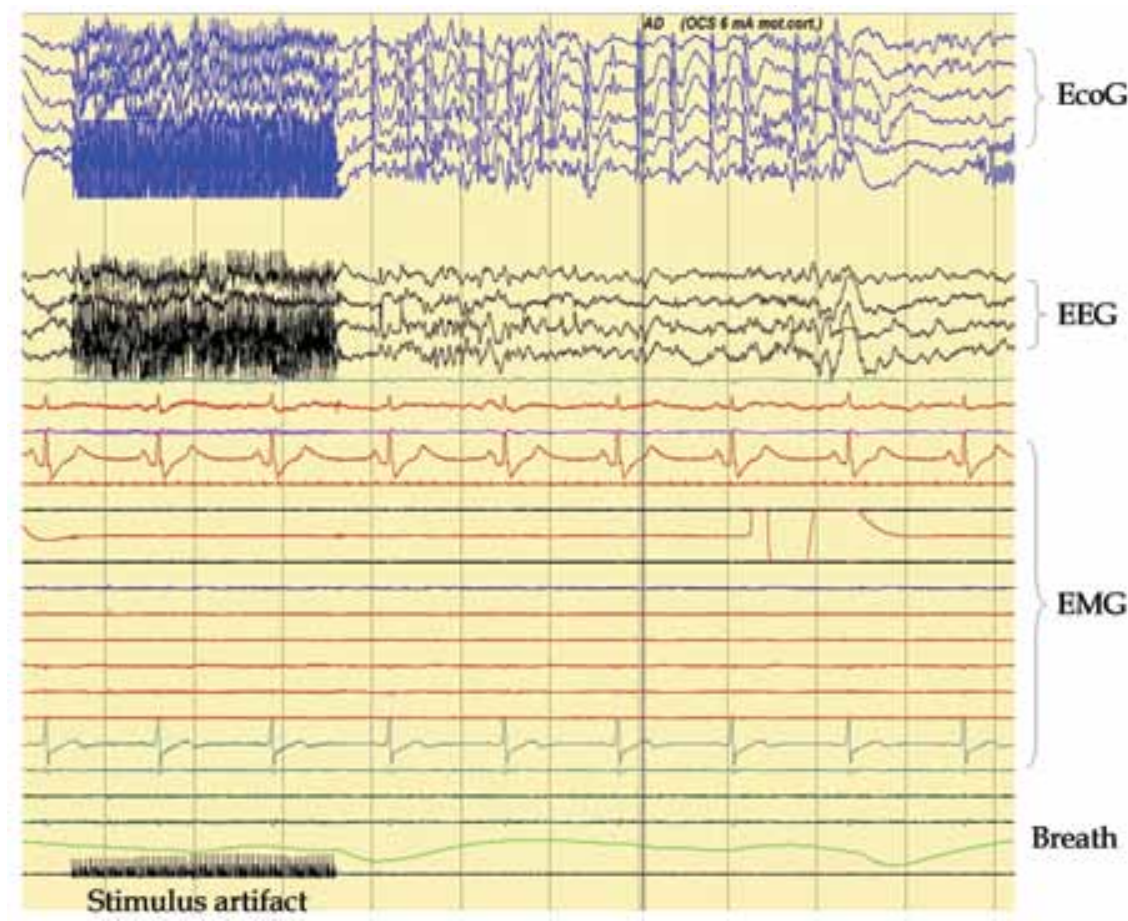

Fig. 5. Asleep surgery ECoG (Traces 1-6), surface electroencephalography (Traces 7-10), and EMG traces (remaining traces) obtained during $60-\mathrm{Hz}$ stimulations $(6 \mathrm{~mA})$ of the primary motor cortex, showing nonconvulsive seizure activity.

MEPs. Motor evoked potentials must be recorded either with needle electrodes, preferably the same in use for continuous EMG assessment, or-if believed more convenient in awake patients-with surface EMG electrodes. The method's advantage lies in the independence of a patient's compliance and the ability to distinguish between lesions of the supplementary and those of the primary motor area. ${ }^{51}$ Moreover, MEPs are useful for preventing vascular injury in insular and/or deep temporal regions, where critical arteries are at risk during tumor resection. ${ }^{34}$ Test clamping can even be performed. The intraoperative use of direct cortical stimulation via a strip electrode to elicit MEPs can be performed repeatedly. As simultaneous cortical and subcortical stimulation can lead to false results, one must ensure that none of the methods is applied simultaneously.

Note that the same stimulation parameters (shorttrain technique with interstimulus interval of $4 \mathrm{msec}$ ) used for continuous MEP monitoring from a strip electrode can be used for cortical (anodal stimulation) and subcortical (cathodal stimulation) mapping from a handheld monopolar probe. This option represents a valid alternative to the classic $60-\mathrm{Hz}$ technique with the advantage of a lower risk of intraoperative seizures (see Side Effects). Nevertheless, the widespread use of the shorttrain technique during awake surgery is just starting and has recently been reported as a possibility for language testing in awake patients. ${ }^{3}$

\section{Cognitive and Language Function}

For cognitive and language tasks, either spontaneous speech or the continuous completion of standardized tasks can be performed. It is beyond the scope of this paper to provide a detailed description and philosophy of the tests being utilized at different centers.

\section{Side Effects}

Long-lasting side effects due to intraoperative brain stimulation have not been reported..$^{22}$ Seizures are the most common side effects and can be harmful to the patient, although there have been no reports of serious injury due to intraoperative seizures. Interestingly, seizures are easily terminated with the direct application of iced Ringer lactate onto the cortex ${ }^{44}$ Longer stimulus durations can induce seizures and are related to the occurrence of afterdischarges at low stimulation intensities. Although preoperative epilepsy is expected to be related to an increased occurrence of intraoperative seizures, there are no data supporting this assumption. ${ }^{45}$ Intraoperative seizures most frequently develop in patients with lesions involving the rolandic and prerolandic areas. Furthermore, they are more frequent with $50-60 \mathrm{~Hz}$ of stimulation than with the train-of-five technique. ${ }^{45}$ The neurosurgeon should consider changing the stimulation modality in patients who are prone to have seizures during mapping.

The resection procedure and instruments, such as the bipolar coagulation probe or the CUSA, can mimic nonconvulsive seizure-related transient disturbance of a patient's performance. Reportedly, the use of the CUSA can interfere with motor and language mapping, inducing a transient masking of active sites. ${ }^{9}$ Therefore, the simultaneous use of CUSA and bipolar coagulation and stimulation should be avoided. 


\section{Controversies in Mapping}

Size of Craniotomy

A recent publication described a tailored craniotomy with sole exposure of the tumor region, language mapping of the exposed area, and guidance by positive and negative stimulation results, ${ }^{42}$ with excellent effects. Note that this procedure has been established by a team with vast experience in cortical mapping and thus should only be relied on if the cortical stimulation technique is well established within the mapping team.

\section{Electrocorticography Recording}

The simultaneous recording of ECoG is used to determine spontaneous or stimulation-induced epileptic discharges, so-called afterdischarges that can occur after electrical stimulation of the cortical areas to detect nonconvulsive seizures (Fig. 5). As a rule, current used for cortical mapping should not exceed certain thresholds to avoid the possibility of misleading false-positive mapping results. Unfortunately, afterdischarge thresholds vary across the cortex. ${ }^{49}$ For certain cortical sites, mapping may be successful only at currents above the afterdischarge thresholds. ${ }^{39}$ Therefore, although ECoG is recommended by most to improve the reliability of mapping and to prevent intraoperative seizures, it also has some limitations that should be remembered during mapping. Still other authors have reported vast experience with successful mapping in a large group of patients without the use of ECoG. ${ }^{17}$ To compromise between the efficacy of mapping and the afterdischarge thresholds, different stimulus durations and/or repetition rates may have to be used.

\section{Focality of Stimulation}

From studies of transcranial magnetic stimulation and direct cortical stimulation in tumor surgery, it is known that the excitation of cortical motor areas other than the primary motor cortex (M1) requires higher intensities. ${ }^{27}$ Nevertheless, in intraoperative practice, the most practical and sufficient way is to determine the motor threshold and use this stimulation intensity for further mapping. ${ }^{11,14}$

\section{Effectiveness of Monitoring and Mapping}

A recent meta-analysis has underlined the growing evidence of the positive relation among the extent of tumor removal, the tumor progression-free interval, and the 5-year survival rate. ${ }^{43}$ Despite the lack of Class 1 evidence, the effect of confounding factors, such as tumor histology and the intraoperative utilization of neurophysiological methods, has not been investigated in the studies included in the meta-analysis. Subcortical mapping has been proven useful in several studies; $4,12,13,17,19,26$ thus, the deduction that it can help in maximizing the extent of tumor resection may be obvious.

\section{Utilization of DT Imaging}

As the extent of tumor removal seems to be important for a patient's overall survival, preoperative imaging for planning the resection becomes more and more impor- tant. Authors have analyzed relations between subcortical mapping and DT imaging. ${ }^{5,29}$ A positive correlation has been found between a stimulation intensity of 8-12 $\mathrm{mA}$ and a $<6-\mathrm{mm}$ distance between the stimulation site and visualized tracts. Nevertheless, the estimated distance between DT imaging and the location of stimulation is influenced by the inaccuracies of DT imaging, the invasiveness of the tumor, intraoperative brain shift affecting navigation accuracy, and the various stimulation parameters and probe types used. Up to now, only subcortical stimulation allows for the in situ real-time assessment of subcortical tracks.

\section{Conclusions}

The $50-$ or $60-\mathrm{Hz}$ stimulation performed with a biphasic pulse and a bipolar stimulation probe is the most widely applied technique for mapping motor and cognitive function during awake surgery. The additional application of the MEP short-train technique broadens the stimulation strategies being used, especially in patients who are not fully compliant or those suffering preexisting partial neurological and developing partial deficits, which can impair intraoperative testing. The main advantage of this technique is the possibility of performing both mapping and continuous MEP monitoring while minimizing the risk of intraoperative seizures. The utilization of those short-train stimulation parameters for cognitive mapping is in its infancy. The relatively short duration of the stimulus has to be timely presented to interfere with the function being tested. Close clinical observation and guidance of the patient combined with recording of EMG activity allows for the best documentation of the mapping procedure.

\section{Disclosure}

The authors report no conflict of interest concerning the materials or methods used in this study or the findings specified in this paper.

Conception and design: A Szelényi, H Duffau, E Fava, G Feigl, G Neuloh, F Sala. Drafting the article: A Szelényi, G Feigl, G Neuloh, F Sala. Critically revising the article: A Szelényi, L Bello, H Duffau, E Fava, G Feigl, M Galanda, G Neuloh, F Signorelli, F Sala. Reviewed final version of manuscript and approved it for submission: A Szelényi, L Bello, H Duffau, E Fava, G Feigl, M Galanda, G Neuloh, F Signorelli, F Sala.

\section{Acknowledgments}

The authors are grateful to Adrian Praeger for his help in English editing.

European Low-Grade Glioma Network Collaborators: L. Capelle, M.D., Paris, France; H. Colle, M.D., Ghent, Belgium; G. Conesa, M.D., Barcelona, Spain; D. Fontaine, M.D., Ph.D., Nice, France; N. Foroglou, M.D., Ph.D., Thessaloniki, Greece; V. Lubrano, M.D., Toulouse, France; E. Mandonnet, M.D., Montpellier, France; A. McEvoy, M.D., London, United Kingdom; S. Momjian, M.D., Genève, Switzerland; J. Pallud, M.D., Paris, France; I. Radovanovic, M.D., Genève, Switzerland; P. A. Robe, M.D., Liege, Belgium; E. Robert, Ghent, Belgium; S. G. Robles, M.D., Madrid, Spain; F. E. Roux, M.D., Ph.D., Toulouse, France; G. J. van Rutten, M.D., Ph.D., Tilburg, The Netherlands; M. Sabel, M.D., Ph.D., Düsseldorf, Germany; K. Schaller, M.D., Ph.D., Genève, Switzerland; M. Skrap, M.D., Udine, Italy; G. Spena, M.D., Genève, Switzerland. 


\section{References}

1. Agnew WF, McCreery DB: Considerations for safety in the use of extracranial stimulation for motor evoked potentials. Neurosurgery 20:143-147, 1987

2. Agnew WF, Yuen TG, Pudenz RH, Bullara LA: Electrical stimulation of the brain. IV. Ultrastructural studies. Surg Neurol 4:438-448, 1975

3. Axelson HW, Hesselager G, Flink R: Successful localization of the Broca area with short-train pulses instead of 'Penfield' stimulation. Seizure 18:374-375, 2009

4. Bello L, Acerbi F, Giussani C, Baratta P, Taccone P, Songa $\mathrm{V}$, et al: Intraoperative language localization in multilingual patients with gliomas. Neurosurgery 59:115-125, 2006

5. Bello L, Gambini A, Castellano A, Carrabba G, Acerbi F, Fava E, et al: Motor and language DTI fiber tracking combined with intraoperative subcortical mapping for surgical removal of gliomas. Neuroimage 39:369-382, 2008

6. Berger MS: Functional mapping-guided resection of lowgrade gliomas. Clin Neurosurg 42:437-452, 1995

7. Berger MS, Ojemann GA, Lettich E: Neurophysiological monitoring during astrocytoma surgery. Neurosurg Clin $\mathbf{N}$ Am 1:65-80, 1990

8. Berger MS, Rostomily RC: Low grade gliomas: functional mapping resection strategies, extent of resection, and outcome. J Neurooncol 34:85-101, 1997

9. Carrabba G, Mandonnet E, Fava E, Capelle L, Gaini SM, Duffau $\mathrm{H}$, et al: Transient inhibition of motor function induced by the Cavitron ultrasonic surgical aspirator during brain mapping. Neurosurgery 63:E178-E179, 2008

10. Cushing H: A note upon the faradic stimulation of the postcentral gyrus in conscious patients. Brain 32:44-53, 1909

11. Duffau H: Acute functional reorganisation of the human motor cortex during resection of central lesions: a study using intraoperative brain mapping. J Neurol Neurosurg Psychiatry 70:506-513, 2001

12. Duffau H: A personal consecutive series of surgically treated 51 cases of insular WHO Grade II glioma: advances and limitations. J Neurosurg 110:696-708, 2009

13. Duffau H, Capelle L, Denvil D, Sichez N, Gatignol P, Taillandier L, et al: Usefulness of intraoperative electrical subcortical mapping during surgery for low-grade gliomas located within eloquent brain regions: functional results in a consecutive series of 103 patients. J Neurosurg 98:764-778, 2003

14. Duffau H, Capelle L, Sichez J, Faillot T, Abdennour L, Law Koune JD, et al: Intra-operative direct electrical stimulations of the central nervous system: the Salpêtrière experience with 60 patients. Acta Neurochir (Wien) 141:1157-1167, 1999

15. Duffau H, Capelle L, Sichez N, Denvil D, Lopes M, Sichez JP, et al: Intraoperative mapping of the subcortical language pathways using direct stimulations. An anatomo-functional study. Brain 125:199-214, 2002

16. Duffau H, Gatignol P, Denvil D, Lopes M, Capelle L: The articulatory loop: study of the subcortical connectivity by electrostimulation. Neuroreport 14:2005-2008, 2003

17. Duffau H, Gatignol P, Mandonnet E, Capelle L, Taillandier L: Intraoperative subcortical stimulation mapping of language pathways in a consecutive series of 115 patients with Grade II glioma in the left dominant hemisphere. J Neurosurg 109:461-471, 2008

18. Duffau H, Lopes M, Arthuis F, Bitar A, Sichez JP, Van Effenterre R, et al: Contribution of intraoperative electrical stimulations in surgery of low grade gliomas: a comparative study between two series without (1985-96) and with (1996-2003) functional mapping in the same institution. J Neurol Neurosurg Psychiatry 76:845-851, 2005

19. Eisner W, Burtscher J, Bale R, Sweeney R, Koppelstätter F, Golaszewski S, et al: Use of neuronavigation and electrophysiology in surgery of subcortically located lesions in the senso- rimotor strip. J Neurol Neurosurg Psychiatry 72:378-381, 2002

20. Foerster O, Penfield W: The structural basis of traumatic epilepsy and results of radical operations. Brain 53:99-119, 1930

21. Fritsch G, Hitzig E: Über die elektrische Erregbarkeit des Grosshirns. Archiv Anat Physiol Wiss Med 37:300-332, 1870

22. Gordon B, Lesser RP, Rance NE, Hart J Jr, Webber R, Uematsu S, et al: Parameters for direct cortical electrical stimulation in the human: histopathologic confirmation. Electroencephalogr Clin Neurophysiol 75:371-377, 1990

23. Hern JE, Landgren S, Phillips CG, Porter R: Selective excitation of corticofugal neurones by surface-anodal stimulation of the baboon's motor cortex. J Physiol 161:73-90, 1962

24. Ilmberger J, Eisner W, Schmid U, Reulen HJ: Performance in picture naming and word comprehension: evidence for common neuronal substrates from intraoperative language mapping. Brain Lang 76:111-118, 2001

25. Katayama Y, Tsubokawa T, Maejima S, Hirayama T, Yamamoto T: Corticospinal direct response in humans: identification of the motor cortex during intracranial surgery under general anaesthesia. J Neurol Neurosurg Psychiatry 51:50 59, 1988

26. Keles GE, Lundin DA, Lamborn KR, Chang EF, Ojemann G, Berger MS: Intraoperative subcortical stimulation mapping for hemispherical perirolandic gliomas located within or adjacent to the descending motor pathways: evaluation of morbidity and assessment of functional outcome in 294 patients. $\mathbf{J}$ Neurosurg 100:369-375, 2004

27. Kombos T, Suess O, Kern BC, Funk T, Hoell T, Kopetsch O, et al: Comparison between monopolar and bipolar electrical stimulation of the motor cortex. Acta Neurochir (Wien) 141:1295-1301, 1999

28. Kombos T, Süss O: Neurophysiological basis of direct cortical stimulation and applied neuroanatomy of the motor cortex: a review. Neurosurg Focus 27(4):E3, 2009

29. Leclercq D, Duffau H, Delmaire C, Capelle L, Gatignol P, Ducros $\mathrm{M}$, et al: Comparison of diffusion tensor imaging tractography of language tracts and intraoperative subcortical stimulations. Clinical article. J Neurosurg [epub ahead of print September 11, 2009; DOI: 10.3171/2009.8.JNS09558], 2009

30. Lüders HO, Dinner DS, Morris HH, Wyllie E, Comair YG: Cortical electrical stimulation in humans. The negative motor areas. Adv Neurol 67:115-129, 1995

31. Merrill DR, Bikson M, Jefferys JG: Electrical stimulation of excitable tissue: design of efficacious and safe protocols. J Neurosci Methods 141:171-198, 2005

32. Nathan SS, Sinha SR, Gordon B, Lesser RP, Thakor NV: Determination of current density distributions generated by electrical stimulation of the human cerebral cortex. Electroencephalogr Clin Neurophysiol 86:183-192, 1993

33. Neuloh G, Pechstein U, Cedzich C, Schramm J: Motor evoked potential monitoring with supratentorial surgery. Neurosurgery 54:1061-1072, 2004

34. Neuloh G, Pechstein U, Schramm J: Motor tract monitoring during insular glioma surgery. J Neurosurg 106:582-592, 2007

35. Neuloh G, Schramm J: Monitoring of motor evoked potentials compared with somatosensory evoked potentials and microvascular Doppler ultrasonography in cerebral aneurysm surgery. J Neurosurg 100:389-399, 2004

36. Ojemann G, Ojemann J, Lettich E, Berger M: Cortical language localization in left, dominant hemisphere. An electrical stimulation mapping investigation in 117 patients. J Neurosurg 71:316-326, 1989

37. Penfield W, Boldrey E: Somatic motor and sensory representation in the cerebral cortex of man as studied by electric stimulation. Brain 60:389-443, 1937 
38. Phillips CG, Porter R: Unifocal and bifocal stimulation of the motor cortex. J Physiol 162:532-538, 1962

39. Pouratian N, Cannestra AF, Bookheimer SY, Martin NA, Toga AW: Variability of intraoperative electrocortical stimulation mapping parameters across and within individuals. J Neurosurg 101:458-466, 2004

40. Pudenz RH, Bullara LA, Jacques S, Hambrecht FT: Electrical stimulation of the brain. III. The neural damage model. Surg Neurol 4:389-400, 1975

41. Pudenz RH, Bullara LA, Talalla A: Electrical stimulation of the brain. I. Electrodes and electrode arrays. Surg Neurol 4:37-42, 1975

42. Sanai N, Mirzadeh Z, Berger MS: Functional outcome after language mapping for glioma resection. N Engl J Med 358:18-27, 2008

43. Sanai N, Polley MY, Berger MS: Insular glioma resection: assessment of patient morbidity, survival, and tumor progression. Clinical article. J Neurosurg 112:1-9, 2010

44. Sartorius CJ, Berger MS: Rapid termination of intraoperative stimulation-evoked seizures with application of cold Ringer's lactate to the cortex. Technical note. J Neurosurg 88:349_ 351, 1998

45. Szelényi A, Joksimovic B, Seifert V: Intraoperative risk of seizures associated with transient direct cortical stimulation in patients with symptomatic epilepsy. J Clin Neurophysiol 24:39-43, 2007

46. Szelényi A, Kothbauer K, de Camargo AB, Langer D, Flamm ES, Deletis V: Motor evoked potential monitoring during cerebral aneurysm surgery: technical aspects and comparison of transcranial and direct cortical stimulation. Neurosurgery 57 (4 Suppl):331-338, 2005

47. Szelényi A, Langer D, Kothbauer K, Camargo AB, Flamm ES, Deletis V: Monitoring of motor evoked potentials during cerebral aneurysm surgery: intraoperative changes and postoperative outcome. J Neurosurg 105:675-681, 2006

48. Taniguchi M, Cedzich C, Schramm J: Modification of cortical stimulation for motor evoked potentials under general anesthesia: technical description. Neurosurgery 32:219-226, 1993

49. Uematsu S, Lesser R, Fisher RS, Gordon B, Hara K, Krauss GL, et al: Motor and sensory cortex in humans: topography studied with chronic subdural stimulation. Neurosurgery 31:59-71, 1992

50. Yingling CD, Ojemann S, Dodson B, Harrington MJ, Berger MS: Identification of motor pathways during tumor surgery facilitated by multichannel electromyographic recording. J Neurosurg 91:922-927, 1999

51. Zentner J, Hufnagel A, Pechstein U, Wolf HK, Schramm J: Functional results after resective procedures involving the supplementary motor area. J Neurosurg 85:542-549, 1996

Manuscript submitted October 14, 2009.

Accepted December 7, 2009.

Address correspondence to: Andrea Szelényi, M.D., Department of Neurosurgery, Johann Wolfgang Goethe University Hospital, Schleusenweg 2-16, D-60528 Frankfurt am Main, Germany. email: A.Szelenyi@em.uni-frankfurt.de. 